DOE/ER/ $45365--1$

DE92 008430

\title{
MECHANISMS OF TRANSFORMATION TOUGHENING
}

\author{
Progress Report
}

for Period 1 August, 1988 - 31 July, 1989

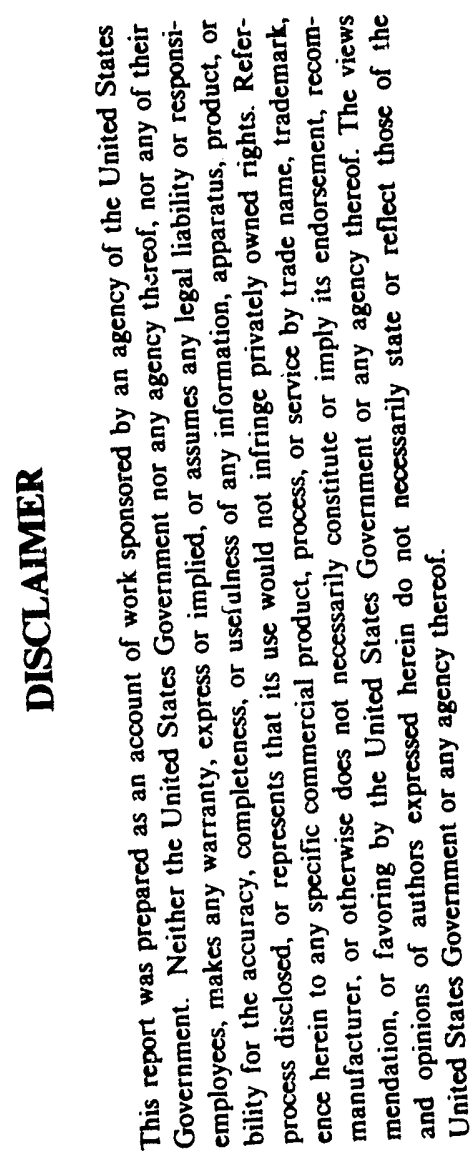

Gregory B. Olson

Northwestern University

Evanston, Illinois 60208

February, 1992

Prepared for

The U. S. Department of Energy

Agreement No. DE-FG02-88ER45365

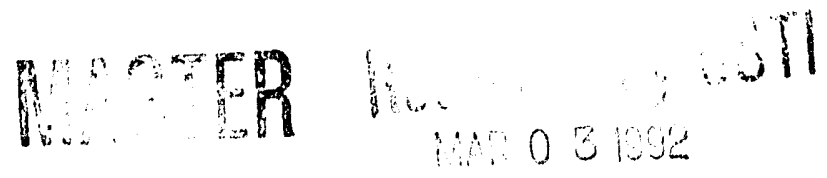


To: Dr. J. Darby, Jr.

Division of Materials Sciences

Office of Basic Energy Sciences

Department of Energy

ER-13-1 G236, GTN

19901 Germantown Rd.

Germantown, MD 20874

Re: Progress Report for DOE Grant DE-FG02-88ER45365

for Period 1 August 1988 to 31 July 1989

Dear Dr. Darby:

Personnel involved in our research program in the subject period included Prof. G.B. Olson as Principal Investigator and Prof. D.M. Parks of MIT as Subcontract Principal Investigator. Dr. Gautam Ghosh joined the program in January, 1989 as Research Associate, part-time (50\%), modelling the thermodynamics and kinetics of isothermal martensitic transformation under stress. Graduate research assistants included Frode Stavehaug working on transformation toughening in austenitic steels, and Mitch Brandt working on dispersed phase transformation plasticity in low alloy steels, as well as Rich Stringfellow at MIT working with Prof. Parks on transformation plasticity constitutive modelling.

Frode Stavehaug's study of transformation toughening in $\gamma^{\prime}$-strengthened austenitic steels continues to focus on room temperature behavior of a series of alloys in which transformation stability is varied with alloy composition. Elevated temperature precracking is employed to avoid crack-tip transformation prior to monotonic loading. Although preliminary experiments indicated record toughness levels of $\mathrm{J}_{\mathrm{IC}}=1000 \mathrm{~kJ} / \mathrm{m}^{2}$ at $1350 \mathrm{MPa}$ yield strength, fractography and crack-tip sectioning showed that high temperature precracking in air produced an irregular branched crack morphology indicative of corrosion fatigue. Using the mechanical testing central facilities at Northwestern, fixtures have been prepared to allow precracking in vacuum and inert atmospheres, and these experiments are now underway. Metallographic sectioning of the specimens precracked in air confirms the absence of martensitic transformation during precracking, and clearly shows the fine strain-induced martensite formed during monotonic loading. Measured transformation zone heights vs. applied J have been compared with previous results in other alloys to quantify the alloy transformation stabilities. All transformation toughening measurements obtained thusfar in austenitic steels strengthened both by $\gamma^{\prime}$ precipitation ${ }^{1}$. and phosphocarbide precipitation (the latter investigated in the previous doctoral research of Chune-Ching Young ${ }^{2}$ ) have been correlated to identify the roles of transformation hardening and dilatancy. Figure 1 shows the transformation toughening increment measured as a function of transformation zone half-height in both types of alloy. The slope $\mathrm{d} \Delta \mathrm{J} / \mathrm{dh}$ of these plots defines a transformation toughening efficiency which is plotted in Figure 2 as a function of transformation volume change. The results fall on two curves representing two levels of austenite/martensite hardness difference. While an increased hardness difference (promoting higher transformation hardening) gives higher toughening, the toughening is even more sensitive to dilation $\Delta v / v$, indicating a dependence on $\Delta v / v$ to the third power. 'This is a stronger dependence on dilation than that exhibited in brittle materials ${ }^{3}$. TEM observations of materials strained to near failure indicate a direct interaction of transformation with the process of microvoid nucleation at submicron particles. A manuscript is in preparation describing these results 4 . 


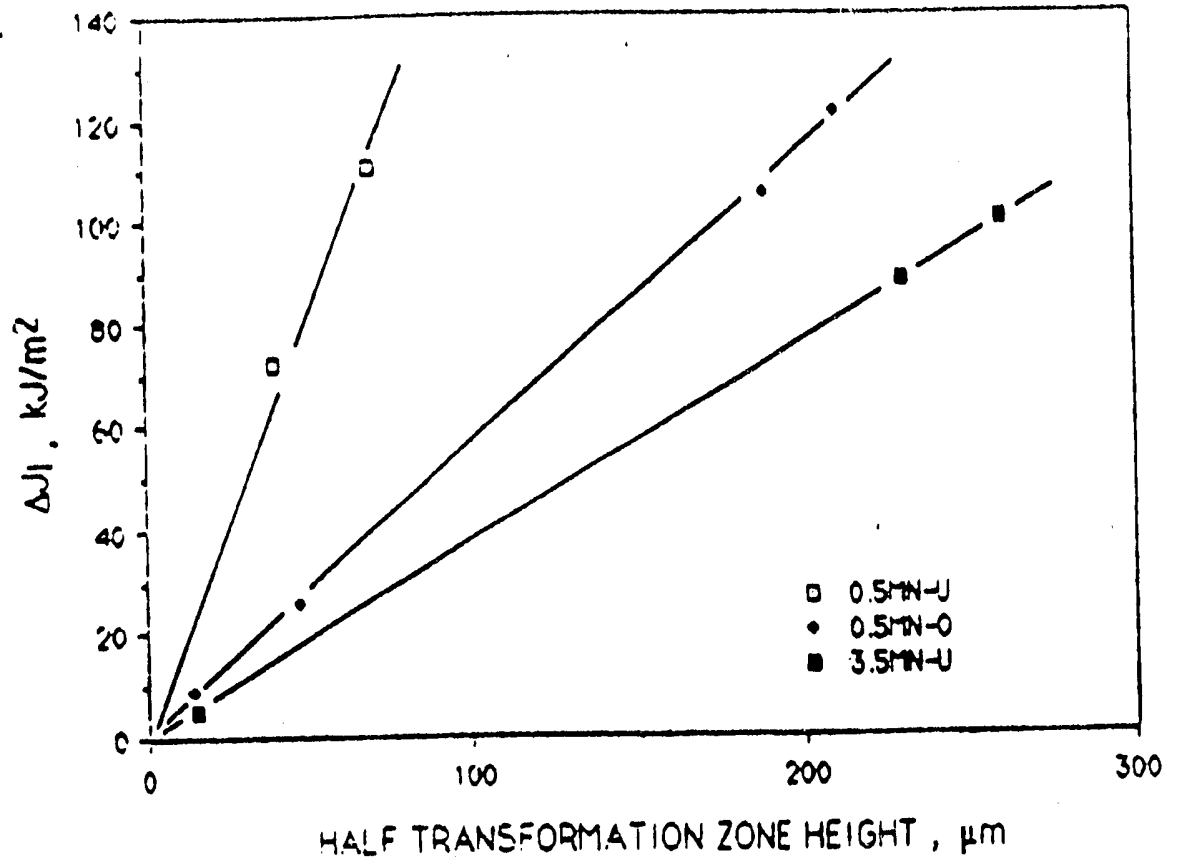

a

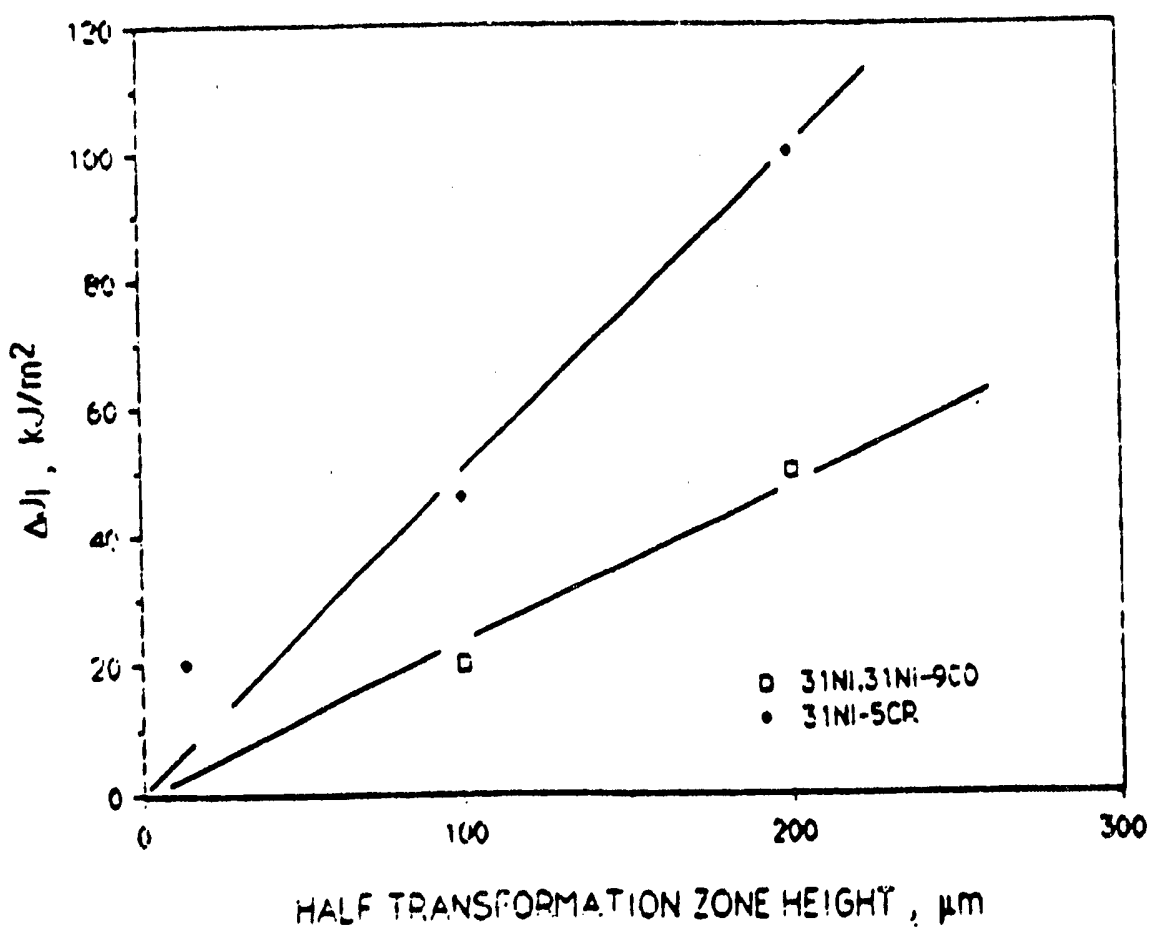

b

Figure 1 Half-height of transformation zone ys. J increment corresponding to j veru smell crack extension $\left(=2 \mathrm{~J} / \mathrm{C} / / .6 \sigma_{\mathrm{j}}\right)$. o). Dhosphocartidestrerigthened steels, (1), y-strengthened steels. 


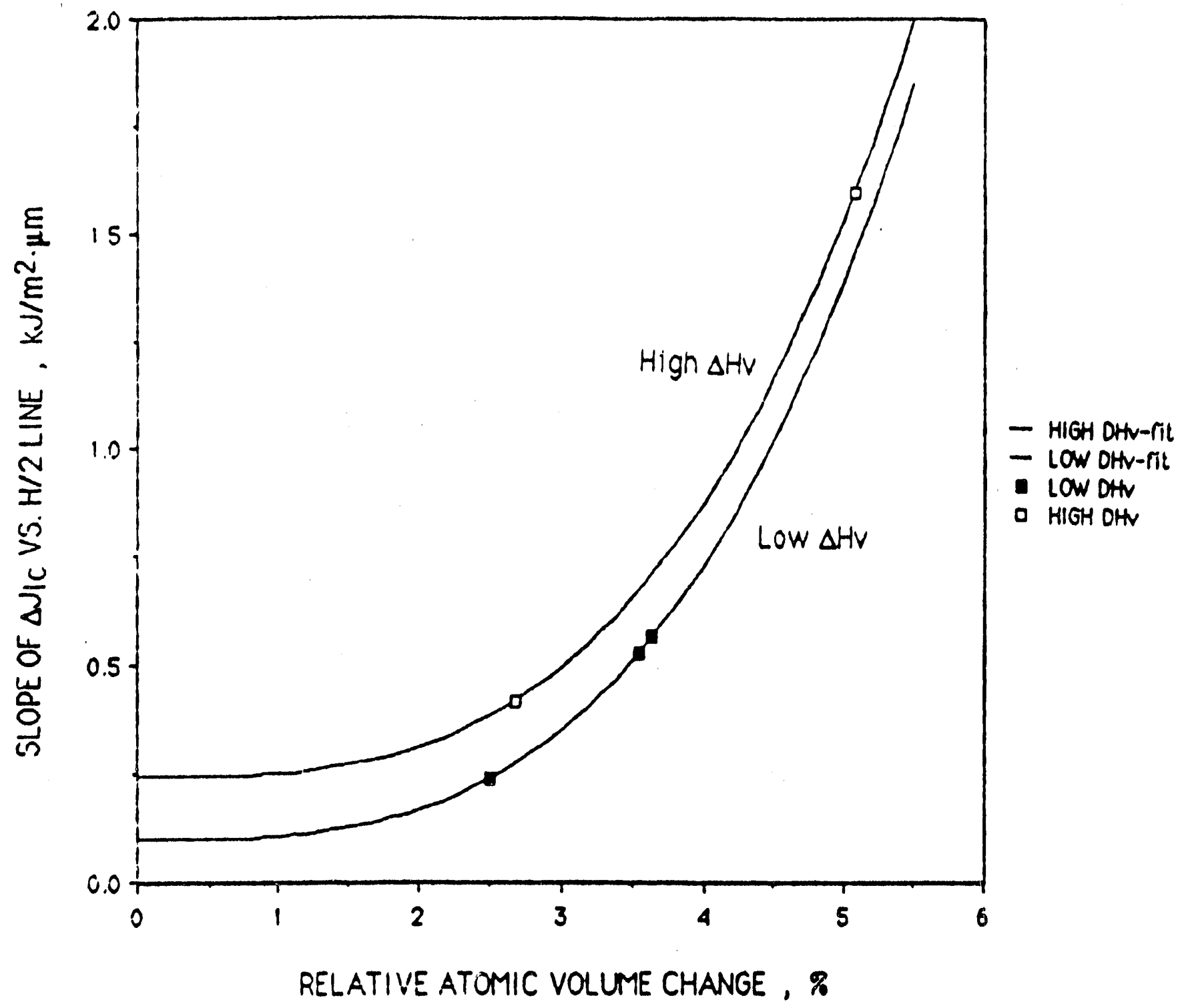

Figure 2 Slopes of hali-height of transformation zone vs. J/ increment lines are plotted transformation volume change for both high- and $10 \mathrm{H}-\Delta \mathrm{HV}$ alloys, and then iitted 10 power equations as shown by solid lines. 
Transformation kinetic models have been extensively re-evaluated. The strain induced kinetic data obtained in the doctoral research of Chune-Ching Young confirmed an expected difference in behavior in uniaxial tension and compression, but which was not consistent with observed behavior for the crack-tip stress state. In part to resolve this discrepancy, Dr. Dennis Haezebrouck undertook in the previous year a detailed refinement of our transformation kinetic model ${ }^{5}$, incorporating a statistically based nonlinear stress dependence of mechanical driving force derived earlier by Dr. Kaneaki Tsuzaki6. The new incremental model also included the variation of mechanical driving force with strain hardening, and allowed for varying stress state paths during deformation. Despite the increased complexity, the new model gives behavior which is not consistent with observed transformation saturation behavior, and is not as accurate as simpler models which treat the driving force as dependent on a stress state ratio $\left(\sigma_{n} / \bar{\sigma}\right)$. Directions considered for further refinement include the transformation inhibiting influence of the increased dislocation density associated with austenite strain hardening, and the role of thermal activation in martensitic nucleation. To explore these aspects at a more fundamental level, Dr. Gautam Ghosh has initiated an analysis of available isothermal nucleation kinetic data for plate martensites which allow a separation of the roles of applied elastic stress and plastic prestrain. Also considered is the effect of solid-solution strengthening which can give temperature dependent activation parameters.

Much progress has been made in the past year in the development of new transformation plasticity constitutive models which incorporate the earlier simpler transformation kinetic models. A manuscript detailing these developments by Rich Stringfellow and Prof. Parks at MIT is in preparation?. A self-consistent model for the deformation behavior of a "static" (constant phase fraction) two-phase mixture has been derived and tested against available date for ferrite-martensite "dual-phase" steels. The model was then extended to "dynamic" transforming two-phase mixtures incorporating a nucleation softening contribution of a form previously employed by Hutchinson and Tvergarrd 8 .for void softening. In contrast to our previous empirical constitutive model ${ }^{9}$ which treated nucleation softening as a stress increment scaling with transformation rate $\mathrm{df} / \mathrm{d} \varepsilon$, the new model introduces the nucleation effect as a plastic strain rate contribution which is more amenable to numerical analysis. Application to the original data obtained by Naratuni ${ }^{9}$ for an annealed austenitic steel is shown in Figure 3. The new model also incorporates rate effects in a viscoplastic approximation.

A new direction of our research in the past year has been the incorporation into this program of an effort previously initiated at MIT under NSF sponsorship directed at extension of our transformation plasticity theory to dispersed-phase systems based on lowalloy steels. The research constitutes the "B Program" of the multi-institutional Steel Research Group (SRG) effort involving interaction with IIT, General Motors, Bethlehem and Inland Steel, and the Army Materials Technology Laboratory (MTL). Guided by the ultimate objective of science-based design of a new class of high-strength, high-formability sheet steels of interest for lightweight automobile applications, the research is focussed on two areas: (a) to test the applicability in dispersed-phase systems of the transformation plasticity theories we are developing in homogeneous alloys, and (b) to control diffusional transformation phenomena to achieve in simple alloy compositions the microstructures which our models predict to be optimal for achievement of desired transformation plasticity properties. In the previous Master's research of Yukio Kuroda ${ }^{10}$ our earlier model of nucleation statistics ${ }^{6}$ was found adequate to describe the strain-induced transformation behavior of $\mathrm{Fe}$ particles in $\mathrm{Cu}$, employing a strain dependence of the nucleation-site potency distribution amplitude similar to that describing strain-induced transformation of homogeneous systems 5 . The model was also applied to available data from GM for strain 


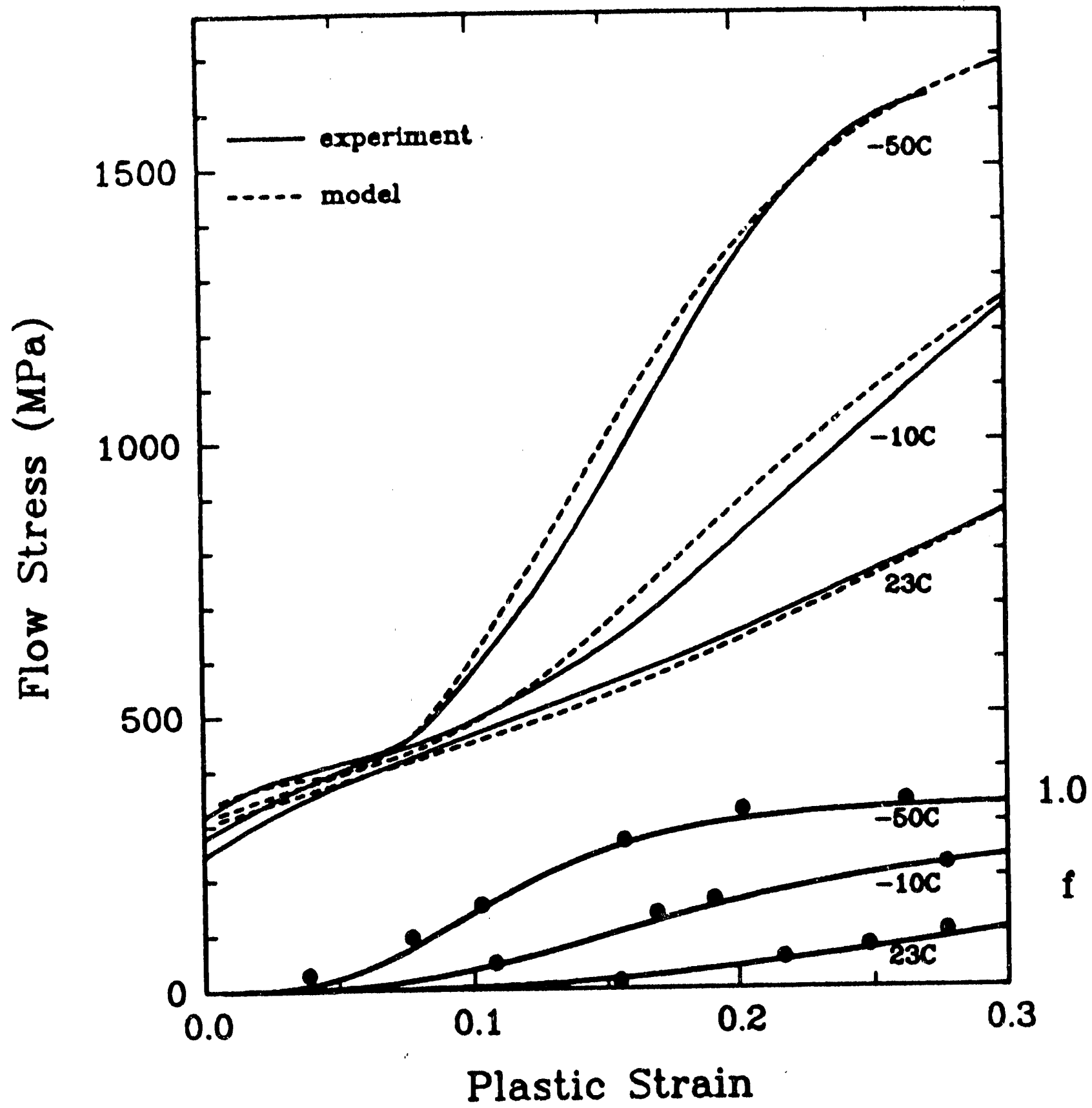

Figure 3 True stress versus strain; comparison of model predictions with experiment at several temperatures in the strain-induced range for a $14 \mathrm{Cr}-7 \mathrm{Ni} .12 \mathrm{C}$ transforming alloy (Narutani, et al., 1982) 
induced transformation in low alloy sheet steels". Our initial efforts at achieving dispersed-phase microstructures of predicted optimal transformation stability have centered on the formation of fine Mn-enriched austenite particles by the paraequilibrium (full substitutional solute trapping) conversion of Mn-enriched cementite particles in tempered martensitic Fe-Mn-Si-C steels ${ }^{12}$. This work continued in the past year in collaboration with Dr. John Beatty of MTL. Recent results were presented at the 1989 TMS-AIME Annual meeting, quantifying the kinetics of Mn enrichment of cementite during recrystallization of cold-worked martensitic structures ${ }^{13}$. Austenite formation from cementite of desired $\mathrm{Mn}$ content is now under investigation. Dr. Indra Gupta of Inland Steel and Prof. G.R. Speich of IIT have assessed recent literature findings of austenite stabilization via bainitic transformation after intercritical annealing. Although the resulting carbon-stabilized austenite is not likely to achieve the high transformation stability levels ultimately attainable from $\mathrm{Mn}$ enrichment, the bainitic transformation technique is of interest for its compatability with current process technology and as a convenient material for studying dispersed-phase transformation plasticity behavior. Compositions of interest have been selected for processing at Inland. Graduate research assistant Mitch Brandt, who will test the predicted stress-state dependence of uniform ductility in these materials, has designed specimens and test fixtures to allow comparison of transformation stability and flow behavior in plane-strain and uniaxial tensile deformation. The principles established will ultimately allow design of austenite dispersions to maximize uniform ductility in the near plane-strain stress states that limit sheet formability.

Respectfully submitted,

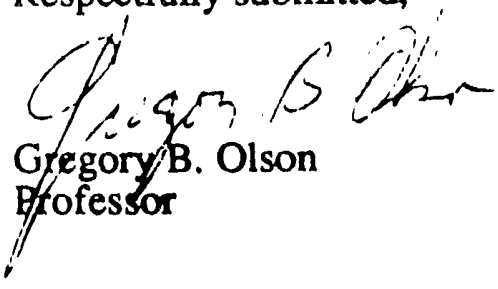


References

*denotes papers stemming from this program (including previous program at MIT)

*1. G.B. Olson and M. Cohen, "Martensitic Transfortintion as a Deformation Process," Earl R. Parker Symposium on Structure/Property Relationships, ed. S.D. Antalovich, W.W. Gerberich, and R.O. Ritchie, TMS-AIME, Warrendale, PA (1986) 367.

*2. Chune-Ching Young, "Transformation Toughening in PhosphocarbideStrengthened Austenitic Steels," Ph.D Thesis, MIT, May 1988.

3. B. Budiansky, J.W. Hutchinson, and J.C. Lambropoulos, Int'l J. Solids and Structures, 19 (1983) 337.

*4. C-C. Young, R.H. Leal, G.B. Olson, and M. Cohen, "Transformation Toughening in Precipitation-Strengthened Austenitic Steels," in preparation.

5. G.B. Olson and M. Cohen, "Kinetics of Strain-Induced Martensitic Transformation," Met. Trans A. 6A (1975) 791.

*6. G.B. Olson, K. Tsuzaki, and M. Cohen, "Statistical Aspects of Martensitic Nucleation," Turnbull Symposium: Phase Transitions in Condensed Systems, ed. G.S Cargill, F. Spaepen, and K.N. Tu, MRS (1987) 129.

*7. R.G. Stringfellow and D.M. Parks, "A Self-Consistent Model of Isotropic Viscoplastic Behavior in Multiphase Materials," in preparation.

8. J.W. Hutchinson and V. Tvergaard, "Softening Due to Void Nucleation in Metals," in preparation.

9. T. Narutani, G.B. Olson, and M. Cohen, "Constitutive Flow Relations for Austenitic Steels During Strain-Induced Martensitic Transformation," J.de Physique 43 (1982) C4-429.

*10. Y. Kuroda, "Kinetics of Deformation-Induced Transformation of Dispersed Austenite in Two Alloy Systems," M.S. Thesis, MIT, June, 1987.

11. A.K. Sachdev, "Effect of Retained Austenite on the Yielding and Deformation Behavior of a Dual Phase Steel," Acta Met. 31 (1983) 2037.

12. M.A. Buonanno, "Austenite Stabilization in Low-Alloy Steels," M.S. Thesis, MIT, June, 1987.

*13. J.H. Beatty and G.B. Olson, "Reversion of Mn Enriched Cementite to Austenite During Intercritical Anneals of a Low Mn Steel," presented at 118th TMS-AIME Annual Meeting, Las Vegas, NV, February 28, 1989. 
To: Dr. J. Darby, Jr.

Division of Materials Sciences

Office of Basic Energy Sciences

Department of Energy

ER-13-1 G236, GTN

19901 Germantown Rd.

Germantown, MD 20874

Re: Progress Report for DOE Grant DE-FG02-88ER45365

for Period 1 August 1988 to 31 July 1989

Dear Dr. Darby:

Personnel involved in our research program in the subject period included Prof. G.B. Olson as Principal Investigator and Prof. D.M. Parks of MIT as Subcontract Principal Investigator. Dr. Gautam Ghosh joined the program in January, 1989 as Research Associate, part-time (50\%), modelling the thermodynamics and kinetics of isothermal martensitic transformation under stress. Graduate research assistants included Frode Stavehaug working on transformation toughening in austenitic steels, and Mitch Brandt working on dispersed phase transformation plasticity in low alloy steels, as well as Rich Stringfellow at MIT working with Prof. Parks on transformation plasticity constitutive modelling.

Frode Stavehaug's study of transformation toughening in $\gamma$-strengthened austenitic steels continues to focus on room temperature behavior of a series of alloys in which transformation stability is varied with alloy composition. Elevated temperature precracking is employed to avoid crack-tip transformation prior to monotonic loading. Although preliminary experiments indicated record toughness levels of $\mathrm{J}_{\mathrm{IC}}=1000 \mathrm{~kJ} / \mathrm{m}^{2}$ at $1350 \mathrm{MPa}$ yield strength, fractography and crack-tip sectioning showed that high temperature precracking in air produced an irregular branched crack morphology indicative of corrosion fatigue. Using the mechanical testing central facilities at Northwestern, fixtures have been prepared to allow precracking in vacuum and inert atmospheres, and these experiments are now underway. Metallographic sectioning of the specimens precracked in air confirms the absence of martensitic transformation during precracking, and clearly shows the fine strain-induced martensite formed during monotonic loading. Measured transformation zone heights vs. applied J have been compared with previous results in other alloys to quantify the alloy transformation stabilities. All transformation toughening measurements obtained thusfar in austenitic steels strengthened both by $\gamma^{\prime}$ precipitation $^{1}$. and phosphocarbide precipitation (the latter investigated in the previous doctoral research of Chune-Ching Young ${ }^{2}$ ) have been correlated to identify the roles of transformation hardening and dilatancy. Figure 1 shows the transformation toughening increment measured as a function of transformation zone half-height in both types of alloy. The slope $\mathrm{d} \Delta \mathrm{J} / \mathrm{dh}$ of these plois defines a transformation toughening efficiency which is plotted in Figure 2 as a function of transformation volume change. The results fall on two curves representing two levels of austenite/martensite hardness difference. While an increased hardness difference (promoting higher transformation hardening) gives higher toughening, the toughening is even more sensitive to dilation $\Delta v / v$, indicating a dependence on $\Delta v / v$ to the third power. This is a stronger dependence on dilation than th rhibited in brittle materials ${ }^{3}$. TEM observations of materials strained to near failure indicate a direct interaction of transformation with the process of microvoid nucleation at submicron particles. A manuscript is in preparation describing these results ${ }^{4}$. 

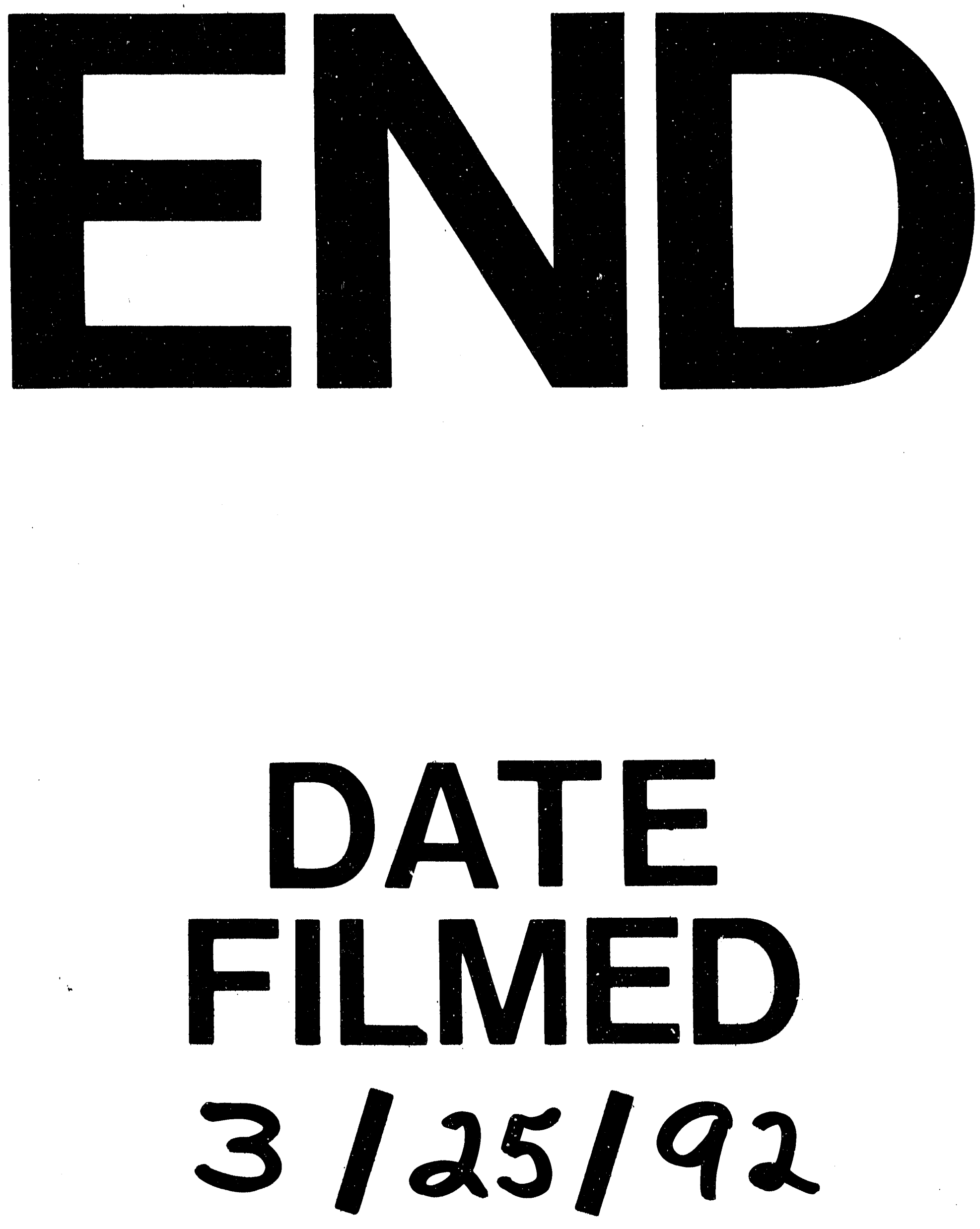

I 
